\title{
Dynamics of plant parasitic and free living nematode populations in sugarcane Saccharum officinarum in Fiji
}

\author{
N. Prasad ${ }^{1}$ and R. Kant ${ }^{2}$ \\ ${ }^{1}$ Sugar Research Institute of Fiji, Drasa, Lautoka, Republic of Fiji Island \\ ${ }^{2}$ Plant \& Food Research, Private Bag 92169, Auckland 1142, New Zealand \\ Corresponding author: Rashmi.Kant@plantandfood.co.nz
}

Parasitic nematodes are one of the main constraints in the production of sugarcane, Saccharum officinarum, in Fiji and other sugarcane-growing countries. Both plant parasitic and free-living nematodes are associated with roots of the plant, and the level of infestation affects both soil health and cane yield. This study examined the dynamics of plant parasitic and free-living nematode populations in sugarcane crops in Drasa Estate, Lautoka, Fiji. Soil samples to quantify nematode populations were collected five times during the crop cycle. There was an exponential increase in the plant parasitic nematode population with time after planting (nematode population $=64.316 \mathrm{e}^{0.0112 \mathrm{x}} ; \mathrm{R}^{2}=0.56, \mathrm{x}=$ days after planting). However, the increase was not consistent among the different nematode groups. Significant increases in Lesion $(\mathrm{P}<0.05)$, Rootknot $(\mathrm{P}<0.05)$, Spiral $(\mathrm{P}<0.01)$, and Ring $(\mathrm{P}<0.03)$ nematode populations were found but not for Reniforms $(\mathrm{P}>0.05)$. Populations of free-living nematodes built up 90 days after planting and remained elevated in the ratoon crop. Populations of parasitic nematodes increased with the growth of cane (as measured by cane height) with increases occurring faster in the ratoon than in the plant crop $(\mathrm{P}=0.001)$. The number of free-living nematodes may have affected population growth of parasitic nematodes.

\section{The relationship between Epiphyas postvittana (lightbrown apple moth, Lepidoptera: Tortricidae) in pipfruit orchards and adjacent vineyards in Nelson}

\author{
P.W. Shaw and D.R. Wallis
}

\section{Plant \& Food Research, Old Mill Road, RD 3 Motueka 7198, New Zealand Corresponding author: peter.shaw@plantandfood.co.nz}

The lightbrown apple moth (Epiphyas postvittana) is the most abundant leafroller species infesting apple orchards and vineyards in the Nelson region. This study was undertaken to investigate concerns from some orchardists of leafroller pressure on their apple blocks adjacent to neighbouring vineyards. Lightbrown apple moth pheromone trap catches were recorded inside orchards and in neighbouring vineyards and in boundary rows of the orchards closest to a vineyard during 2012-13. The vineyards were not treated with insecticide and the orchards received five applications of insecticide between November and midMarch to control lepidopteran pests. The highest catches of leafrollers were recorded in vineyards and catches increased during the season to peak in April. The increasing leafroller population in vineyards was associated with higher catches of leafrollers in boundary rows of the orchard closest to the vineyard. Leafroller catches inside the orchards were lower while insecticide sprays were being applied. The higher pheromone trap catches of leafrollers in the vineyards and on the orchard boundary were associated with the most leafroller sign that was found in these locations during timed searches. These results suggest that high populations of leafrollers in vineyards can increase leafroller pressure on nearby pipfruit orchards. 